\title{
TIPE-TIPE MORFOLOGI TUMBUHAN RAWA LEBAK DI KELURAHAN SEI SELAYUR KECAMATAN KALIDONI SUMATERA SELATAN
}

\author{
Erma Yuniar $^{1}$, Syaiful Eddy ${ }^{2}$, Dewi Rosanti ${ }^{3}$ \\ ${ }^{1,2,3}$ Program Studi Biologi, Fakultas Matematika dan Ilmu Pengetahuan Alam \\ Universitas PGRI Palembang \\ *e-mail: ermayuniar14@yahoo.com
}

\begin{abstract}
The study which examined the morphological structure of lebak swamp in Sei Selayur Sub-district, Kalidoni Sub-district, South Sumatra, was conducted in March to June 2020. This study aims to find out the morphological types of swamp plant morphology in Sei Selayur Sub-District, Kalidoni SubDistrict, South Sumatra. Research using survey methods. Data is collected by exploring directly to 4 stations determined purposively, based on the presence of lebak marsh. Observations were made on the characteristics of roots, leaves, stems, flowers and fruit and organ modification. The results found 20 species of swamp plants. Morphological structures of plants found were observed including roots, leaves, stems, fruits, flowers and their modified organs.
\end{abstract}

Keywords: lebak marsh, root morphology, stem, leaf, flower, fruit, modification

\begin{abstract}
ABSTRAK
Penelitian yang mengkaji struktur morfologi tumbuhan rawa lebak di Kelurahan Sei Selayur Kecamatan Kalidoni Sumatera Selatan telah dilaksanakan pada bulan Maret sampai Juni 2020. Penelitian ini bertujuan untuk mengetahui tipe-tipe morfologi tanaman rawa lebak di Kelurahan Sei Selayur Kecamatan Kalidoni Sumatera Selatan. Penelitian menggunakan metode survey. Pengambilan data dilakukan dengan menjelajahi langsung ke 4 stasiun yang ditentukan secara purposive, berdasarkan keberadaan rawa lebak. Pengamatan dilakukan terhadap karakteristik akar, daun, batang, bunga dan buah serta organ modifikasi. Hasil penelitian ditemukan 20 spesies tumbuhan rawa. Tumbuhan yang ditemukan diamati struktur morfologinya meliputi akar, daun, batang, buah, bunga dan organ modifikasinya.
\end{abstract}

Kata kunci : rawa, morfologi akar, batang, daun, bunga, buah/biji, modifikasi. 


\section{PENDAHULUAN}

Lahan rawa merupakan sebuah bentuk ekosistem yang dimana sangat kompleks, bagian dari alam pada hamparan bumi yang memiliki peran dam siklus yang biogeokimia globan dan sangat penting bagi ekosistem global. Lahan rawa ini memiliki biodiversitas yang cukup tinggi, sehingga perlindungan lahan rawa ini menjadi salah satu kegiatan yang sangat mendesak untuk dilakukan di seluruh dunia (Harianto et al., 2017).

Indonesia memiliki lebak yang cukup sangat luas yang sekitar 13,27 juta ha dan baru sebagian kecil atau yang kurang dari satu juta ha yang telah berhasil dimanfaatkan. Lebak ini terutama tersear di tiga pulau besar yaitu, Pulau Sumatera, Pulau Kalimantan, dan Pulau Papua. Di sisi lain, potensi yang terdapat di lahan rawa sangatlah cukup besar, dengan seluas 33,4 juta ha, tersebar di Sumatera 32,9\%, Kalimantan 40,4\%, Papua 21\%, Sulawesi $5,7 \%$ dan sisanya akan tersebar di secara parsial pada di areal yang cukup kecil yang akan dapat dioptimalkan menjadi lahan pertanian. Lahan rawa saat ini luasnya sekitar 33,4 juta ha, dan sekitar 914 juta ha diantaranya disediakan untuk pertanian, namun baru 5,27 ha yang telah dimanfaatkan. Lahan rawa ini terdiri atas lahan rawa pasang surut (20,1 juta ha) dan lahan rawa lebak (13,3 juta ha) yang akan berpotensi untuk dikembangkan sebagai penghasil pangan dan komoditas lainnya di Indonesia. Pengaruh perubahan iklim di lahan rawa ini sangatlah berbeda tergantung tipologi lahan. (Nursyamsi et al., 2014).

Eddy et al., (2019) total keanekaragaman spesies dari semua 8 area pengambilan sampel yang hanya terdiri dari 20 tanaman dan memiliki 14 familia. Ada 10 spesies mangrove sejati, yaitu: Acanthus ilicifolius, Avicennia alba, Sarcolobus globose, Nypa fruticans, Excoecaria agallocha, Sonneratia alba,
Xylocarpus granatum, Acrostichum aureum, Bruguiera cylindrical, dan Rhizophora apiculate. Yang lainnya adalah spesies mangrove yang sudah jarang ditemukan di vegetasi hutan mangrove.

Oktaviani et al., (2015) melaporkan beberapa analisis vegetasi herba rawa lebak pada bekas lahan persawahan di jalan Palembang-Indralaya dan terdiri dari 3 suku yaitu Cyperaceae, Graminaceae dan Asteraceae. Sedikitnya jumlah familia dan spesies tumbuhan rawa yang telah ditemukan menunjukkan rendahnya nilai keanekaragaman vegetasi yang ada di rawa lebak tersebut.

Puspasari (2012) menyebut lahan rawa lebak ini sebagai danau-danau dataran banjir yang akan mempunyai dasar lebih luas dari sungai pada umumnya dan selalu akan mendapatkan luapan air dari sungai-sungai besar seperti sungai Barito (Kalimantan Selatan), Kahayan (Kalimantan Tengah), Kapuas (Kalimantan Barat), Mahakam (Kalimantan Timur), Musi (Sumatera Selatan), Batanghari (Jambi), dan Digul (Papua).

\section{METODE PENELITIAN}

Penelitian ini dilaksanakan pada Maret sampai Juni 2020, berlokasi di lahan rawa lebak di Kelurahan Sei Selayur Kecamatan Kalidoni Sumatera Selatan.Metode yang akan digunakan dalam penelitiam ini adalah metode survey dengan menjelajahi seluruh area rawa yang ditemukan diidentifikasi dan dideskripsikan struktur morfologinya meliputi akar, batang, bunga, buah/biji, dan organ modifikasi.

\section{HASIL DAN PEMBAHASAN}

Diperoleh 20 species tumbuhan rawa yang tumbuh di Kelurahan Sei Selayur Kecamatan Kalidoni dengan 
sebaran sebagaimana ditampilkan pada tabel 1 berikut ini :

Tabel 1. Sebaran spesies tumbuhan rawa lebak di kawasan Kelurahan Sei Selayur Kecamatan Kalidoni Sumatera Selatan.

\begin{tabular}{|c|c|c|c|c|c|c|}
\hline \multirow[t]{2}{*}{ No } & \multirow[t]{2}{*}{ Spesies } & \multirow[t]{2}{*}{ Nama Lokal } & \multicolumn{4}{|c|}{ Stasiun Pengamatan } \\
\hline & & & 1 & 2 & 3 & 4 \\
\hline 1. & Cylosorus arisdus $\mathrm{L}$ & Pakis Kadal & $\checkmark$ & & & \\
\hline 2. & Stenochlaena palustris L. & Pakis Udang & & & $\sqrt{ }$ & \\
\hline 3. & Lophatherum gracile L. & Rumput Bambu & & $\checkmark$ & & \\
\hline 4. & Pistia spratiotes $\mathrm{L}$. & Apu-apu & & & $\sqrt{ }$ & \\
\hline 5. & Amaranthus spinosus L. & Bayam Duri & & & $\sqrt{ }$ & \\
\hline 6. & Amaranthus spinosus L. & Bandotan & $\checkmark$ & & & \\
\hline 7. & Phyllanthus niruri L. & Meniran & & & & $\checkmark$ \\
\hline 8. & Ipomoea aquatic L. & Kangkung & & & & $\sqrt{ }$ \\
\hline 9. & Mikania micrantha L. & Sembung Rambat & $\checkmark$ & & & \\
\hline 10. & Cyperus rotundus L. & Rumput Teki & & & & $\checkmark$ \\
\hline 11. & Ruellia tuberosa $\mathrm{L}$. & Pletesan & $\checkmark$ & & & \\
\hline 12. & Peperomia pellucida $\mathrm{L}$. & Sasaladahan & & $\sqrt{ }$ & & \\
\hline 13. & Acalypha indica & Kucingan & $\checkmark$ & & & \\
\hline 14. & Colocasia esculenta L. & Keladi & & & $\sqrt{ }$ & \\
\hline 15. & Eichhornia crassipes L. & Eceng Gondok & & $\sqrt{ }$ & & \\
\hline 16. & Eclipta alba & Urang Aring & & & & $\sqrt{ }$ \\
\hline 17. & Melaleuca leucadendron L. & Gelam & $\checkmark$ & & & \\
\hline 18. & Muntingia calabura L. & Seri & & $\sqrt{ }$ & & \\
\hline 19. & Oxalis corniculata L. & Semanggi Gunung & & & $\sqrt{ }$ & \\
\hline 20. & Portulaca oleacea L. & Krokot Ait & $\checkmark$ & & & \\
\hline
\end{tabular}


Berdasarkan Tabel 1 di atas, dapat dilihat terdapat 20 spesies tumbuhan rawa yang ditemukan yaitu : pakis kadal (Cylosorus aridus L.), rumput bambu (Lophatherum gracile L.), apu-apu (Pistia stratiotes L.), bayam duri (Amaranthus spinosus L.), bandotan (Ageratum conyzoides L.), meniran (Phyllanthus niruri L.), kangkung (Ipomoea aquatica L.), sembung rambat (Mikania micrantha L.), rumput teki (Cyperus rotundus L.), pletesan (Ruellia tuberosa L.), sasaladahan (Peperomia pellucida L.), Kucingan (Acalypha indica L.), pakis udang (Stenochlaena palustris L.), keladi (Colocasia esculenta L.), eceng gondok (Eichhornia crassipes L.), urang-aring (Eclipta alba L.), gelam (Melaleuca leucadendron L.), seri (Muntingia calabura L.), semanggi gunung (Oxalis corniculata L.), krokot air (Portulaca oleacea L.).

Dilihat dari taksonominya, 18 species termasuk dalam Divisio Spermatophyta. Sedangkan 2 spesies lainnya yaitu pakis udang (Cyclosorus aridus L.) dan pakis kadal (Stenochlaena palustris L.) merupakan species dari Divisio Pteridophyta, yang memang sering ditemukan pada kawasan rawa. .

Menurut Rosanti (2013), tumbuhan (Stenochlaena palustris L.) ditemukan hampir seluruh lahan gambut. Hal ini disebabkan karena habitat tumbuhan rawa yang sesuai dengan kondisi stasiun pengamatan, yaitu kolam, anak sungai, dan kawasan rawa lainnya yaitu : Apu-apu, meniran, kangkung, sembung rambat, teki, pletesan, keladi, eceng gondok, urang aring, dan semanggi gunung.
Morfologi daun (Folium) yang ditemukan adalah struktur daun tunggal (Folium simplex) dan daun majemuk (Folium compositum). Stuktur daun meliputi meliputi bangun daun (Circumscriptio), pangkal daun (Basis folii), ujung daun (Apex folii), tepi daun (Margo folii), system pertulangan daun (Nervatio), daging daun (Intervenium), permukaan daun, warna daun dan tata letak daun (Phyllotaxis).

Morfologi bunga yang ditemukan adalah bunga tunggal (Planta unifloris), dan. bunga majemuk (planta multiflora) yang terdapat pada ketiak daun (Flos axillaris) dan ujung batang (Flos terminalis). Morfologi buah (Fructus) bertipe buah buah sejati.

Bangun daun terdiri dari bulat/bundar, perisai, jorong, lanset, jantung, segitiga, delta, pita. Jenis yang memiliki bangun daun bulat/bundar ditemukan pada apu-apu, eceng gondok. Jenis yang memiliki bangun perisai ditemukan pada keladi. Jenis yang memiliki bangun daun jorong ditemukan pada jenus meniran, pletesan. Jenis yang memiliki bangun daun lanset ditemukan pada pakis kadal, pakis udang, rumput bambu, urang aring, gelam, seri, krokot air. Jenis yang memiliki bangun daun jantung ditemukan pada jenis kangkung, sembung rambat, sasaladahan, semanggi gunung. Jenis yang memiliki bangun daun segitiga ditemukan pada bandotan. Jenis yang memiliki bangun daun delta ditemukan pada jenis bayam duri, kucingan. Jenis yang memiliki bangun daun pita ditemukan pada jenis rumput teki. 
Pangkal daun yang terdiri dari runcing, tumpul, membulat, rompang/rata, berlekuk. Jenis yang memiliki pangkal daun runcing ditemukan pada jenis gelam, semanggi gunung. Jenis yang memiliki pangkal daun tumpul ditemukan pada jenis pakis kadal, pakis udang, rumput bambu, apu-apu, pletesan, kucingan, urang aring, krokot air. Jenis yang memiliki pangkal daun membulat ditemukan pada jenis bayam duri, bandotan, meniran, eceng gondok. Jenis yang memiliki pangkal daun romping/rata ditemukan pada jenis rumput teki. Yang memiliki jenis pangkal daun berlekuk ditemukan pada jenis kangkung, sembung rambat, keladi, seri, sasaladahan.

Ujung daun yang terdiri dari runcing, meruncing, tumpul, membulat, berlekuk. Jenis yang memiliki ujung daun runcing ditemukan pada jenis pakis kadal, pakis udang, rumput bambu, sasaladahan, kucingan, keladi, urang aring, gelam, seri. Jenis yang memiliki ujung daun meruncing ditemukan pada jenis bandotan, rumput teki dan sembung rambat. Jenis yang memiliki ujung daun tumpul ditemukan pada jenis kangkung, bayam duri. Jenis yang memiliki ujung daun membulat ditemukan pada jenus apu-apu, meniran, pletesan, eceng gondok, krokot air. Jenis yang memiliki ujung daun berlekuk ditemukan pada jenis semanggi gunung.

Tepi daun yang terdiri dari rata dan berlekuk. Jenis yang memiliki tepi daun rata ditemukan pada jenis pakis kadal, pakis udang, rumput bambu, apu-apu, bayam duri, menian, kangkung, rumput teki, pletesan, sasaladahan, keladi, eceng gondok, urang aring, gelam, krokot air, semanggi gunung. Jenis yang memiliki tepi daun berlekuk ditemukan pada jenis bandotan, sembung rambat, kucingan, seri.

Daging daun terdiri dari tipis seperti kertas, tipis lunak, kaku, berdaging. Jenis yang memiliki daging daun tipis seperti kertas ditemukan pada jenis pakis kadal, pakis udang, rumput bambi, bandotan, meniran, rumput teki, pletesan, kucingan, keladi, eceng gondok, urang aring, seri, semanggi gunung. Jenis yang memiliki daging daun tipis lunak ditemukan pada jenis bayam duri, kangkung, sembung rambat, sasaladahan. Jenis yang memiliki daging daun kaku ditemukan pada jenis gelam. Jenis yang memiliki daging daun berdaging ditemukan pada jenis apu-apu, krokot air.

Pertulangan daun terdiri dari menyirip, melengkung, lurus/sejajar. Jenis yang memiliki pertulangan daun menyirip terdiri dari pakis kadal, pakis udang, bayam duri, bandotan, meniran, kangkung, sembung rambat, pletesan, kucingan, keladi, urang aring, seri, semanggi gunung, krokot air. Jenis yang memiliki pertulangan daun melengkung ditemukan pada jenis sasaladahan, eceng gondok. Jenis yang memiliki pertulangan daun lurus/sejajar ditemupak pada jenis rumput bambu, apu-apu, rumput teki, gelam.

Warna daun semua spesies yang ditemukan berwarna hijau. Hal ini dapat disebabkan oleh klorofil, klorofil ini menyerap cahaya matahari selama proses fotosintesis. Selama fotosintesis tumbuhan dan pohon menggunakan cahaya matahari untuk mengubah 
karbon dioksida di udara dan air menjadi kaya energy sebagai makanan.

Permukan daun memiliki 2 jenis yang terdiri dari licin dan berbulu. Jenis yang tepi daun terdiri dari rata, berlekuk. Tepi daun rata dimiliki spesies rumput bambu, apu-apu, bayam duri, meniran, kangkung, rumput teki, pletasan, sasaladahan, pakis udang, pakis kadal, keladi, eceng gondok, gelam. Tepi daun berlekuk dimiliki spesies bandotan, sembung rambat, seri. Jenis yang memiliki permukaan daun ditemukan pada jenis bandotan, pletesan, seri, rumput bambu.

Tata letak daun hanya mempunyai ada 2 jenis folio sparsa dan opposite. Jenis yang memiliki tata letak daun folio sparsa ditemukan pada jenis pakis kadal, pakis udang, apu-apu, bayam duri, kangkung, rumput teki, sasaladahan, kucingan, keladi, eceng gondok, gelam, seri, semanggi gunung, krokot air, rumput bambu. Jenis yang memiliki tata letak daun folio opposite ditemukan pada jenis meniran, sembung rambat, pletesan, urang aring, bandotan.

Batang terdiri dari basah, rumput, mendong berkayu, cakram, dan semu. Jenis yang memiliki batang basah ditemukan pada jenis bayam duri, sasaladahan, krokot air. Jenis yang memiliki batang rumput ditemukan pada jenis rumput bambu. Jenis yang memiliki batang mendong ditemukan pada rumput teki. Jenis yang memiliki batang berkayu ditemukan pada bandotan, meniran, sembung rambat, pletesan, kucingan urang aring, gelam, seri, semanggi gunung. Jenis yang memiliki batang cakram ditemukan pada jenis apu-apu, dan eceng gondok.
Bunga hanya ada bunga tunggal, bunga majemuk tidak terbatas dan terbatas. Jenis yang memiliki bunga tunggal ditemukan pada jenis meniran, kangkung, pletesan, seri, krokot air. Jenis yang memiliki bunga majemuk tidak terbatas ditemukan pada jenis eceng gondok. Jenis yang memiliki bunga majemuk berbatas ditemukan pada jenis rumput bambu, apu-apu, bayam duri, bandotan, sembung rambat, rumput teki, sasaladahan, kucingan, keladi, urang aring, gelam, semanggi gunung.

Struktur buah yang ditemukan adalah buah sejati. Buah sejati pada tumbuhan rawa di Kelurahan Sei Selayur Kecamatan Kalidoni Sumatera Selatan terdiri dari buah buni dan buah kotak. Buah buni dimiliki oleh keladi dan seri. Sedangkan buah kotak dimiliki spesies eceng gondok, semanggi gunung, dan krokot air.

Modifikasi hanya ada 3 jenis, yaitu: umbi batang, gelembung, dan sulur dahan. Jenis yang memiliki modifikasi umbi batang terdiri dari jenis keladi. Jenis yang memiliki modifikasi gelembung ditemukan pada jenis eceng gondok. Jenis yang memiliki modifikasi sulur dahan ditemukan pada jenis sembung rambat.

\section{KESIMPULAN}

disimpulkan:

Dari hasil penelitian dapat

1. Jenis-jenis tumbuhan dirawa lebak Kelurahan Kalidoni Kecamatan Kalidoni diperoleh 20 jenis yaitu Lophatherum gracile L., Pistia stratiotes L., Amaranthus spinosus L., Ageratum conyzoides L., 
Phyllanthus niruri L., Ipomoea aquatic L., Mikania micrantha L., Cyperus rotundus L., Ruellia tuberosa L., Peperomia pellucida L., Acalypha indica L., Colocasia esculenta L., Eichhornia crassipes L., L., Melaleuca leucadendron L., Muntingia calabura L., Oxalis corniculata L., Portulaca oleacea L., Cyclosorus aridus L. dan Stenochlaena palustris L.

2. Dilihat dari taksonominya, 18 species termasuk dalam Divisio Spermatophyta .Sedangkan 2 species lainnya yaitu pakis udang Cyclosorus aridus L. dan Stenochlaena palustris L. Merupakan species dari Divisio Pteridophyta, yang memang sering ditemukan pada kawasan rawa.

\section{DAFTAR PUSTAKA}

Eddy. S., M.R. Ridho, I. Iskandar, A. Mulyana. 2019. Species Composition and Structure of Degraded Mangrove Vegetation in the Air Telang Protected Forest, South Sumatra, Indonesia. Jurnal Biodiversitas. Vol. 20 N0. 8. 2119$2127 \mathrm{hlm}$.

Harianto, P. Sugeng., dan D.B. Sari. 2017. Biodiversitas Flora di Kawasan Budidaya Lahan Basah. Lampung: Universitas Lampung.

Nursyamsi, D., M. Noor, dan Haryono. 2014. Sistem Surjan, Model. Pertanian Lahan Rawa Adaptasi Perubahan Iklim. Badan Litbang Pertanian. Kementerian Pertanian. IAARD Pres. Jakarta.
Oktaviani, S.I., D.J. Santri dan E. Dayat. 2015. Keanekaragaman Vegetasi Rawa di Kecamatan Tanjung Lago. Jurnal Lahan Suboptimal. Vol.4 No.2. 133-148 hlm.

Puspasari, L. 2012. Inventarisasi dan Identifikasi Vegetasi Rawa Lebak di Desa Deling Kecamatan Lamapan Kabupaten Ogan Komering Ilir Sumatera Selatan. Skripsi.

Rosanti, D. $2013 \quad$.Morfologi Tumbuhan. Erlangga. Jakarta. 